\title{
A Research on the Landscape Design Of Lighting System
}

\author{
Li Zheng ${ }^{1}$, Yong-gang $A n^{1,2,3^{*}}$, Xiaojing Man ${ }^{1,2,3^{*}}$ \\ ${ }^{1}$ The School of Landscape Architecture, Beijing University of Agriculture \\ ${ }^{2}$ Beijing Engineering Research Center of Rural Landscape Planning and Design, \\ Beijing University of Agriculture \\ ${ }^{3}$ Beijing Collaborative Innovation Center for Eco-environmental Improvement with \\ Forestry and Fruittrees,Beijing University of Agriculture \\ ${ }^{*}$ Corresponding author
}

Keywords: Lighting system,Landscape design, Urban lighting standard

Abstract. With the rapid development of urban landscape design, the lighting is more and more needed. Existing urban landscape and lighting design of the system is not perfect, according to the regulations of city road and park lighting standard to analyze, and the various forms of existing urban landscape and light design combination to research, summarizes the urban landscape and a lighting system combine the design rules of standard, making the night landscape lighting become a system.

\section{Introduction}

People's aesthetic level is gradually improved,the night scene of the city must be developed.The space of the development of lighting industry in China is big, but in the lighting design, the lighting design profession in China started late.Abroad, many developed countries started early night planning, and now it is relatively stable, economic development, more standardized operation, and ensure the final design quality.

\section{The second chapter: lighting and lighting standards}

\section{Types of lighting fixtures}

In urban landscape, lighting systems are used in a variety of lamps, and for different landscape types, we should choose the lamps and lanterns in coordination with them.Type of lamps in the city landscape is: road lamps, garden lights, high pole lamps, sculpture landscape lamp, LED lamp, lawn lamp, floor lamps, wall lamp, underground lamp, underwater lamp, LED lamp, LED lamp with curtain wall etc.

\section{Evolution history and trend of lighting system in urban landscape}

Lighting in the urban landscape design has gone through three processes, before 1997 for the germination period, lighting only to meet the needs of life, 1997 to 2004 for the growth period.Lighting system of parks and tourist attractions such as the landscape environment began to rise, since 2004 the prosperous period, all kinds of new technologies, new style lamps used in many big cities all over the city and building "night" tour mode.

\section{Lighting system standards}

The design standard of landscape lighting for city parks is shown in Table 1,and the standard for design of urban road lighting is shown in Table 2. 
Table 1. Design standard of landscape lighting for city parks

\begin{tabular}{|c|c|c|c|c|c|}
\hline \multicolumn{2}{|c|}{ Landscape lamp type } & \multicolumn{4}{c|}{ Lighting lamps } \\
\cline { 2 - 6 } & Power $(\mathrm{W})$ & type & $3.5-4.5$ & Spacing (M) \\
\hline \multirow{2}{*}{ yard lamp } & With masks & 150 & High pressure sodium lamp & $3.5-4.5$ & $18-20$ \\
\cline { 2 - 6 } & No mask & 150 & Sodium lamp and metal halide lamp & $0.5-0.8$ & 5 \\
\hline \multicolumn{2}{|c|}{ Lawn lamp } & 36 or 70 & Sodium halide lamp & - & - \\
\hline \multicolumn{2}{|c|}{ Floodlight } & 250 & Metal halide lamp & $0.1-0.2$ & $1.8-2$ \\
\hline \multicolumn{2}{|c|}{ Buried lamp } & 20 & Sodium lamp &
\end{tabular}

Table 2. Standard for design of urban road lighting

\begin{tabular}{|c|c|c|c|c|c|c|c|}
\hline \multirow[b]{2}{*}{ level } & \multirow[b]{2}{*}{ Road type } & \multicolumn{2}{|c|}{ Pavement luminance } & \multicolumn{3}{|c|}{ Pavement illumination } & \multirow[b]{2}{*}{$\begin{array}{l}\text { Lamps and } \\
\text { lanterns } \\
\text { selection }\end{array}$} \\
\hline & & $\begin{array}{l}\text { Average } \\
\text { brightness } \\
\text { (Cd/square } \\
\text { meters) }\end{array}$ & $\begin{array}{l}\text { Total } \\
\text { uniformity }\end{array}$ & $\begin{array}{l}\text { Longitudinal } \\
\text { uniformity }\end{array}$ & $\begin{array}{l}\text { Average } \\
\text { illuminance }\end{array}$ & Evenness & \\
\hline I & $\begin{array}{l}\text { The main road } \\
\text { (including the Yingbin } \\
\text { Road, the main road } \\
\text { leading to government } \\
\text { offices and large public } \\
\text { buildings, is located in } \\
\text { the center of the city, } \\
\text { behind the commercial } \\
\text { center road) }\end{array}$ & $1.5 / 2.0$ & 0.4 & 0.7 & $20 / 30$ & 0.4 & $\begin{array}{l}\text { Light cut or } \\
\text { half light } \\
\text { lamps and } \\
\text { lanterns }\end{array}$ \\
\hline II & Secondary roads & $0.75 / 1.0$ & 0.4 & 0.5 & $10 / 15$ & 0.35 & $\begin{array}{l}\text { semi-cut-off } \\
\text { lamps and } \\
\text { lanterns }\end{array}$ \\
\hline III & Access $\mathrm{Rd}$ & $0.5 / 0.75$ & 0.4 & - & $8 / 10$ & 0.3 & $\begin{array}{l}\text { semi-cut-off } \\
\text { lamps and } \\
\text { lanterns }\end{array}$ \\
\hline
\end{tabular}

\section{The third chapter lighting lighting system and landscape design}

\section{Lighting and plant landscape}

In the garden landscape, plants play an important role, act as its hair, is a soft landscape.In urban landscape design, plants are used in many places, and the species of plants are also varied. The colors are rich, and the harmony of plant landscape and lighting can produce very good artistic effects.Many cities with plants as the main body to create three-dimensional landscape with lights, in the city's vertical landscape at night there are bright spots.Holidays, more three-dimensional lighting landscape to form a city features. Lamps and lanterns choose LED lamp belt to surround a plant to model more is shown in Fig 1.

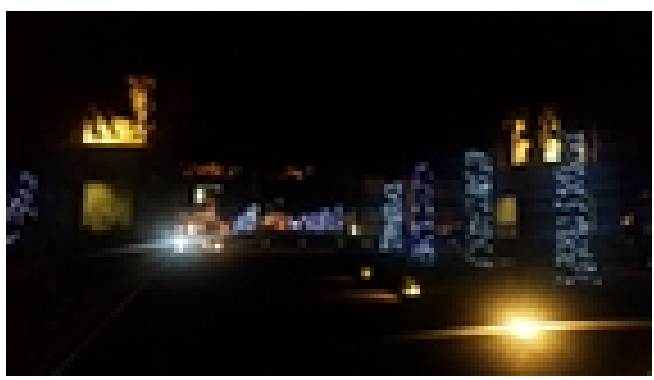

Figure 1. Lights and plants

\section{Lighting and rockery landscape}

The stone sett is a very important subject in the garden landscape, and the selection of stone materials is very important to the final landscape,rare stones such as thin, wrinkled, leaky and transparent are rare.In the city landscape design, the stone is used with the park and municipal area, 
forming integration with the natural landscape, with light color changeable, full of fantastic feeling, unique. Or is the embodiment of the solemn atmosphere of the municipal work area, choose a single piece of stone, night lighting equipment using simple color, contrast the stone mountain landscape and calm atmosphere, the work area of the fusion of temperament.In addition, many hotels are placed in the doorway of rockery, day and night in the light of great momentum, under the effect of added some soft, different colors of light through the natural cave, rockery stone to wear clothes, to enhance the grade of hotel. Choose spotlights to create atmosphere, light, soft and harmonious with the main environment is shown in Fig 2.

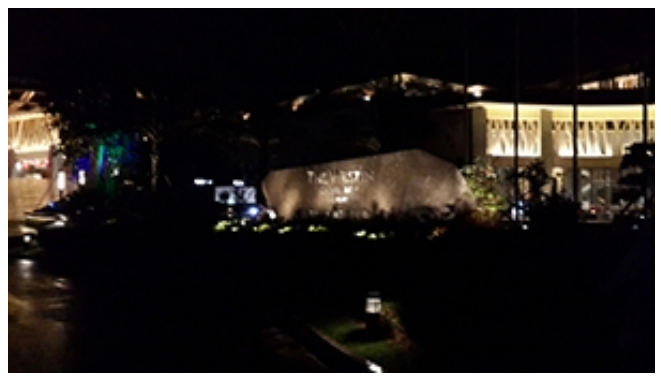

Figure 2. Lights and rockery

\section{Lighting, lighting and water landscape}

Water is good for all things, and no dispute, it is smart and changeable nature of the landscape to become lively and interesting.In the city landscape design, water landscape for active region city population is more intensive, some landscape along the lake, the light is selected and soft colors, contrast the lake quiet atmosphere; some fountain set to landscape, lighting and mobility, a sense of rhythm features and changing style derived from a variety of landscape, such as lighting the music fountain, with water and music perfect rhythm, plus light, simple fountain landscape becomes rich and interesting, to attract more visitors viewing experience.In the water landscape, use waterproof spotlights, placed at the bottom of the pool, Led lamp belt around the pool wall, and water landscape coordination and matching, the color will be in accordance with specific occasions to make color or single color selection is shown in Fig 3.

\section{Lighting, structures, buildings}

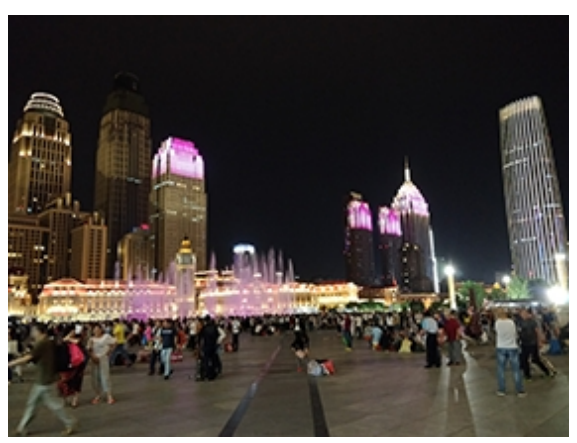

Figure 3. Lights and water landscape

An important role as a skeleton in landscape architecture, landscape wall, door, corridor, pavilion, pavilion, is the best way to transfer cultural markers, and they show the charm of the lights will be exhaustive. In modern landscapes, lighting has more emphasis on the theme.In the urban landscape design, the forms of structure, building and lighting match are the most diverse, and the types of lamps are more abundant, and the final effect are more shocking.In the city's residential area, the entrance is equipped with a view wall of lighting, and the momentum at night is less than during the day.In the center of the city edifice side facade installation LED wall lights, not only lit up the night, when the holidays can also reflect the theme of city lights to transform different characteristics, night viewing effect is very good, increase the sense of fashion for the city is shown in Fig 4. 


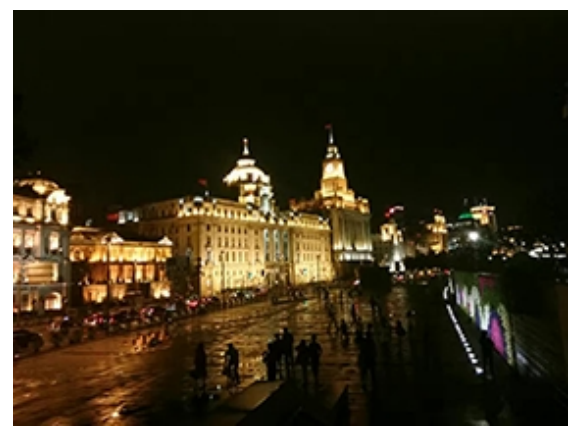

Figure 4. Lighting and architecture

\section{Lighting and lighting landscape}

Where there is light, there will be shadows, and if the light and shade are skillfully matched, a new landscape will be formed.In the city landscape design, the use of lighting the landscape sketches the shadow of injection positions during the day to see the shadow of night landscape landscape static, and create another kind of atmosphere, sunlight and shade people unlimited reverie in the city at night.Modern light and shade landscape in parks, leisure areas to create, use Led spotlights illuminate the shadow, the use of lawn lights and other small light sources, foil atmosphere.

\section{Fourth chapter lighting lighting system in landscape design application standard}

\section{Application standards of lighting in plant landscape design}

The application of lighting in the plant landscape design, the main consideration to the coordination with the plant itself characteristics, and the selection of lamps will not cause harm to the plants, such as some high luminosity high heat lamp and the lamp is not suitable for plant landscape.According to different types and colors of the plants, the choice of lamps to match, taboo light is too bright and robbed the plant landscape plant landscape status, as the body, the lights should be to increase the role of embellishment and bright contrast, the beauty of the shape of plants.

\section{Lighting applications in rockery landscape design standards}

The application of lighting in the rockery landscape design, taking into account the rockery shape and texture of rocks is divided into natural and artificial creation, there are many types of material, the hardness and the transmittance of each stone is different in the choice of lamps to fully consider these factors.For each stone of different colors, lighting choices should be coordinated with them to form the artistic effect of lighting and rockery. The lights in the light rockery form, from different angles and lighting, reflect the texture bump stone, rockery landscape create magnificent momentum.

\section{Application standards of lighting in water landscape design}

The lighting application for the water landscape design, to take into account the features in the form of water, light application for water landscape should be taken into account when each forms of the water landscape water amount and flow variables, to choose the lamp itself has waterproof function, according to the arrangement of different lamps the water landscape location, select underground lights in the water in the water features, choose water lights, color yellow and white, plain light, reflected in the clear water movement.In the design of the fountain landscape, color lamps can be selected to adjust the color with the form of water injection. It is not suitable to choose large light sources such as projection lamps, etc. to destroy the quiet beauty of the water landscape.

\section{Lighting standards applied in landscape design of buildings and structures}

When lighting is applied for the landscape design of buildings and structures, the volume and location of buildings and structures, as well as the history of the building itself should be taken into account.In classical gardens, light is applied to the structure of the landscape. It is better to choose simple atmospheric colors, light sources, light ranges, and soft lights.In the application of light material in the landscape design of large structures, suitable for lighting the high degree of structures according to the location choice of the color of the light, in the crowded area, select the colorful lights in public places and other more serious place, choose a single color.Apply the lights in the urban 
architectural landscape design, select LED lights, form a large area of lighting landscape in the building, create a sequence sense, and highlight the characteristics of urban architecture.

\section{Lighting applications in light and shade landscape design standards}

When lighting is applied for the design of light and shade, we should take into account the projection ratio of light and shadow, and the environment atmosphere created by the light and shade landscapes. The main light in landscape design for plants, sculpture and structures, the most abundant plant shadow, lighting lighting projection lamps suitable for the selection of the angle is very important, find the light objects forming the shadow best position. Underground light can also be used to illuminate the landscape objects, forming a rear projection landscape.

\section{Conclusions}

Based on the analysis of the application of lighting system in landscape design, combined with the existing lighting standards, the application of standard lighting in landscape design, a method of forming the city landscape design landscape lighting, after the city landscape construction landscape lighting design specification, to follow the nature as the base, to achieve low power consumption, low pollution, high reflection of city landscape lighting design beauty. In the various forms of urban landscape design, the landscape as the main body, lighting as an auxiliary, so that the landscape at night to show the city face, lighting and lighting systems and landscape design.

\section{Acknowledgement}

This paper is supported by the following projects:Innovation environment and platform construction (No.5075231016/005);Beijing Collaborative innovation center for eco-environmental improvement with forestry and fruittrees (CEFF-PXM2017_014207_000043);"Internet plus" driven by the research on the upgrading and transformation of the rural tourism industry(No.15JGB055).

\section{Literature References}

[1] Fan Shifu..2004.. The development direction of "light culture" in urban lighting. Journal of illuminating engineering

[2] Kong Haiyan, Yuan Yuan,.2004., garden lighting. Beijing. China Forestry Publishing House

[3] Li Nong,.2010. light changes urban lighting planning and design exploration and practice. Beijing. Science Press

[4] Liang Zheng.2010. city planning: from green to low carbon construction technology.

[5] Horse.2007. garden night landscape research. Master thesis. Yangling: Northwest Agriculture and Forestry University

[6] Zhang Meng. [Master Thesis] Application of lighting art in urban green space in Xi'an

[7] Wang Jianhua..2003.. The basic principles of city nightscape lighting planning. Urban issues

Honkonen V.2006.Architecture of Light.Cities and Landscape

[8] Honkonen V.2006.Architecture of Light.Cities and Landscape 